DOI: 10.12731/2227-930X-2021-11-1-99-113 УДК 69.001.6

\title{
СТРОИТЕЛЬНЫЙ РЫНОК СМОЛЕНСКОЙ ОБЛАСТИ В ПЕРИОД ФИНАНСОВОГО КРИЗИСА И ВЛИЯНИЯ ПАНДЕМИИ
}

\section{Сапожникова С.M.}

В исследовании рассмотрены особенности развития строительной отрасли на региональном уровне, определены основные параметры состояния и перспективы его дальнейшего функиионирования.

Выявлены факторы, влияющие на современные тенденции развития строчтельной отрасли, угрозы и основные проблемы, особенно в условиях мирового экономического кризиса и пандемии. Проведено обследование состояния материально-технической базы строительных компаний и уровень их конкуренции, а также на основе опроса предпринимателей отрасли определен уровень индекса их экономической активности и перспективы формирования строительного портфеля в условиях кризиса и локдауна. На основании чего были предложены меры по совершенствованию регулирования строительного рынка в условиях экономического кризиса и пандемии. Основной вывод исследования состоит в том, что единственным условием эффективного развития и восстановления до предкризисного уровня экономики регионов и ее отраслей, включая строительную, в условиях локдауна является полноченное государственное регулирование, финансирование, национализация и финансовая, юридическая, дипломатическая, информационная защита от внешнего негативного воздействия глобализации и кризиса.

Цель-оценка состояния строчтельного рынка региона, выявление проблем и угроз и предложение мер по его регулированию в условиях локдауна, санкций, экономического кризиса и пандемии. 
Метод или методология проведения работы: в статье использовались методы сравнения, опроса, индексный, графический, методы статистического и факторного анализа.

Результаты: выявлены основные проблемы, угрозы строительного рынка, даны рекомендации по их нейтрализаџии в условиях экономического кризиса и пандемии.

Область применения результатов: полученные результаты целесообразно применять для выбора оптимального управленческого решения при выработке стратегии развития региональной строительной компании.

Ключевые слова: строительство; регион; позичия на рынке; угрозы; стратегия; SWOT-анализ; объем строительных работ; портфель заказов; индекс предпринимательской уверенности

\section{CONSTRUCTION MARKET OF SMOLENSK REGION DURING THE PERIOD FINANCIAL CRISIS AND PANDEMIC IMPACT}

\section{Sapozhnikova S.M.}

The study examines the features of the development of the construction industry at the regional level, defines the main parameters of the state and the prospects for its further functioning.

The factors influencing the current trends in the development of the construction industry, threats and main problems, especially in the context of the global economic crisis and pandemic, are identified. A survey of the state of the material and technical base of construction companies and the level of their competition was carried out, as well as a survey of industry entrepreneurs on changes in the level of their economic activity and the prospects for the formation of a construction portfolio.

On the basis of this, measures were proposed to improve the regulation of the construction market in the context of the economic crisis and pandemic. The main conclusion of the study is that the only con- 
dition for effective development and recovery to the pre-crisis level of the economy of the regions and its industries, including construction, in a lockdown is full government regulation, financing, nationalization and financial, legal, diplomatic, information protection from external negative impact globalization and crisis.

Purpose. The goal is to assess the state of the construction market in the region, identify problems and threats and propose measures to regulate it in the face of a lockdown, sanctions, economic crisis and pandemic.

Methodology: the article used methods of comparison, survey, index, graphic, methods of statistical and factor analysis.

Results: the main problems and threats to the construction market were identified, recommendations were given for their neutralization in the context of the economic crisis and pandemic.

Practical implications: the results obtained should be applied to select the optimal management solution when working out a development strategy for a regional construction company.

Keywords: construction; region; market position; threats; strategy; SWOT analysis; volume of construction work; portfolio of orders; index of entrepreneurial confidence

Строительство - важный элемент современной экономики, включающий создание нового объекта, проведение реконструкции, расширения, достройки, реставрации и ремонта объектов и выполнение монтажных работ; характеризующийся длительными сроками создания продукта, привязкой к месту постройки, большими единовременными капитальными затратами. Вопросами развития строительного рынка активно занимались многие отечественные и зарубежные авторы [1-12].

В региональном строительстве выделяются следующие виды трудовой деятельности: подготовка градостроительных решений, градостроительное зондирование, планировка территории, проведение изысканий, проектирование, строительное производство или строительно-монтажные работы (СМР) заключение контрак- 
тов, финансовое обеспечение, экспертиза, контроль качества, ценовой и технологический аудит, инфраструктурное и коммуникационное обеспечение.

В зависимости от специализации строительные организации функционируют или в отдельном регионе (жилищно-гражданское строительство), узкоспециализированные компании работают на территории региона или территориях других регионов, сооружая объекты в соответствующих отраслях экономики (промышленное строительство - энергетика, транспорт, нефтегазодобывающая промышленность), межрегионально организована инфраструктура - производство строительных материалов, строительных машин и оборудования и т.п.

В настоящее время сложился высокотехнологичный региональный строительный рынок, представляющий собой открытую организационно-хозяйственную систему, межотраслевой хозяйственный комплекс. Его элементы включают субъекты, объекты, инфраструктуру, рыночный механизм, государственный контроль, регулирование и саморегулирование (рис. 1). Эффективность развития строительного рынка зависит от состояния соответствующего сегмента рынка, инвестиционной привлекательности региона, применяемых технологий, квалификации кадров и внешних факторов (нормативно-правовая база, налогообложение, конкуренция и т.п.).

Развитие регионального строительного рынка определило выделение на нем отдельных подсекторов: атомное, транспортное, подземное строительство, строительство объектов электроэнергетики, общестроительные, гидротехнические работы, инженерные сети, монтаж и пусконаладка [16].

В Проекте Стратегии развития строительной отрасли РФ до 2030 г. отмечено, что строительная отрасль находится перед долговременными вызовами , такими, как: конкуренция, технологические изменения, состояние человеческого капитала, исчерпание потенциала экспортно-сырьевой модели экономического развития страны [15]. 


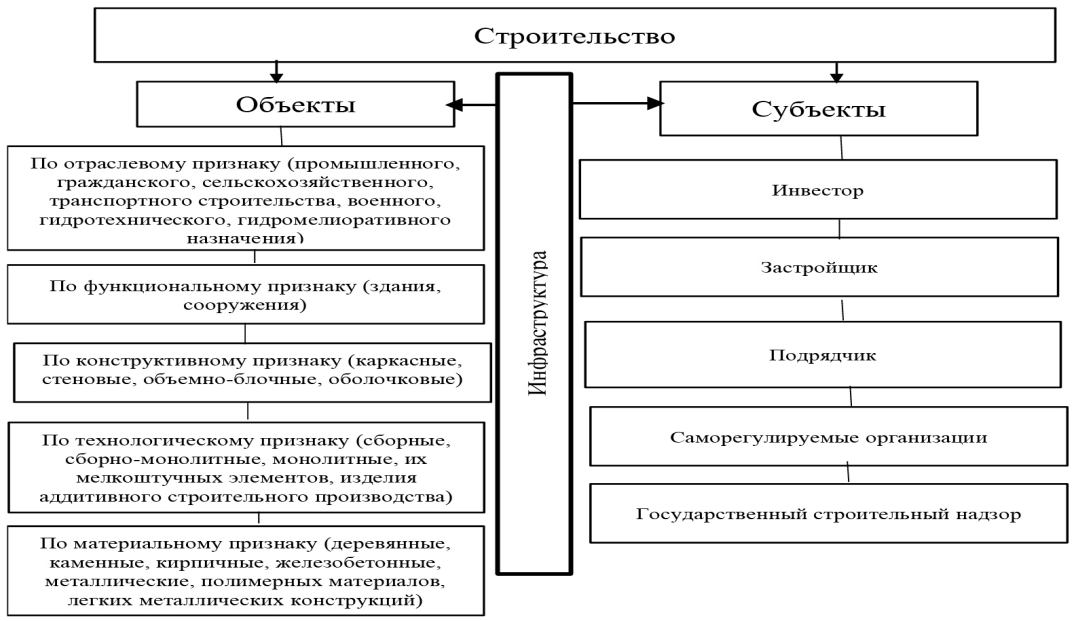

Рис. 1. Элементы регионального строительного регионального рынка

В рамках данной Стратегии происходит развитие строительной отрасли Смоленской области, которое пока имеет достаточно устойчивое положение и определенные перспективы развития. В 2019 г. доля строительства в ВРП составляет около 5\%, тогда как в 2016 г. $-3,1 \%$ (в 2010 г. -.10,2\%)[14] (рис. 2).
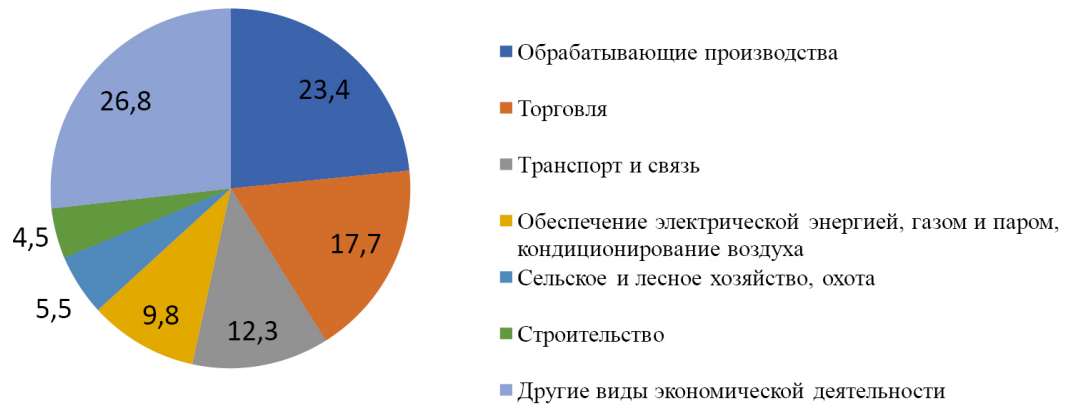

Рис. 2. Структура валового регионального продукта Смоленской области в 2019 г., \%

На строительном рынке Смоленской области в кризис 2020 г. основными угрозами выступают несоответствия нормативных актов современным реалиям (например, по нормативам в размещении парковок, 
по мусоропроводам в МКД при раздельном сборе мусора), сложности привлечения банков к финансированию проектов до 1 млрд. руб. или низкорентабельных строительных компаний и т.п.) и др. Высокие угрозы строительному рынку потребовали проведения консервативной стратегии в условиях кризиса (выполнение ранее взятых обязательств, при ограничении привлечения новых заказов и ассортимента строительного продукта, ведение мер антикризисного управления, сокращения затрат). В структуре затрат строительных компаний в 2019 г. материальные затраты составляют 71,7\% (в 2015 г. - 68,4\%), оплата труда - 13,2\% (17,2\%), страховые взносы - 3,8\% (5,2\%), амортизация $-3,8 \%$ (2,4\%), прочие - 9,2\% (6,7\%), что связано с инфляционными процессами и повышения стоимости строительных материалов. SWOT - анализ строительного рынка в 2020 г. представлен в табл. 1.

Таблицุа 1.

SWOT - анализ строительного рынка Смоленской области

\begin{tabular}{|c|c|}
\hline & \\
\hline $\begin{array}{l}\text { - Высокий спрос и потребность в жилье и } \\
\text { его капремонте, обновления инженерной } \\
\text { инфраструктуры; } \\
\text { - Высокопрофессиональные } \\
\text { государственные контрольные органы, } \\
\text { система саморегулирования; } \\
\text { - Конкурентная цена; } \\
\text { - Обеспеченность строительными } \\
\text { материалами; } \\
\text { - Ипотечное и проектное финансирование; } \\
\text {-региональное образование и подготовка } \\
\text { специалистов отрасли }\end{array}$ & $\begin{array}{l}\text { - Невысокая рентабельно } \\
\text { - Низкая техническая вос } \\
\text { и уровень использования } \\
\text { высокий износ основных } \\
\text { - Некачественная систем } \\
\text { онального планирования } \\
\text { дирования, градостроите } \\
\text { законодательства; } \\
\text { - Недостатки государстве } \\
\text { ниципальных заказов и к }\end{array}$ \\
\hline & \\
\hline $\begin{array}{l}\text { - Вовлечение в оборот неохваченных } \\
\text { территорий в жилищное строительство, } \\
\text { включая сельские территории, в том числе } \\
\text { под дачное строительство; } \\
\text { - Невысокая обеспеченность жильем на } 1 \\
\text { чел. по сравнению с другими странами и } \\
\text { регионами и Проектом Стратегии; } \\
\text { - Современные технологии в строитель- } \\
\text { стве; } \\
\text { - Госпрограммы по расселению из ветхого } \\
\text { жилья; } \\
\text { - Субсидирование ипотечных ставок }\end{array}$ & $\begin{array}{l}\text { - Повышение стоимости строитель- } \\
\text { ной продукции при снижении дохо- } \\
\text { дов потребителей снижает спрос; } \\
\text { - Уменьшение вложений в основной } \\
\text { капитал; } \\
\text { - Рост безработицы и другие факто- } \\
\text { ры финансового кризиса; } \\
\text { - Конкуренция со стороны компаний } \\
\text { из других регионов, потерявшие сво- } \\
\text { их покупателей; } \\
\text { - Недостаточная престижность рабо- } \\
\text { ты в отрасли }\end{array}$ \\
\hline
\end{tabular}


На строительном рынке Смоленской области участвуют компании разных форм собственности, из них преобладают частные предприятия - 98,5\% (на начало 2020 г. из 1293 ед.: государственных - 10, муниципальных - 2, частных - 1273, смешанных -1 , с прочей формой - 7). В распоряжении строительных компаний находятся основные фонды в размере 2142,7 млн. руб. в 2019 г., что выше уровня 2005 г. на 52,6\%. При этом их структура включает: $11,1 \%$ - здания, 49,7\% - оборудование, $37,1 \%$ - транспортные средства, 0,3:- прочие. Но количество техники в собственности снижается (рис. 3).

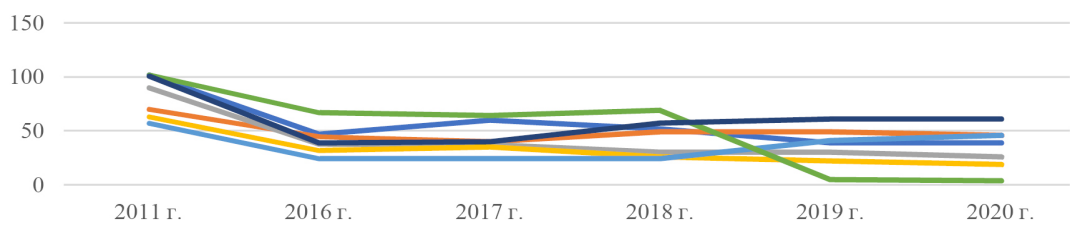

—кскаваторы самоходные одноковшовые
грейдеры самоходные
бульдозеры и бельдозеры с поворотным отвалом
автокраны
погрузчики одноковшовые самоходные
тракторы гусеничные
— катки дорожные самоходные

Рис. 3. Динамика основных строительных машин в строительных организациях Смоленской области, ед.

Износ основных фондов в строительстве достаточно высок: так на конец года в 2019 г. он составляет 57,9\%, что выше показателя 2005 г. на 6,6\%. Ввод в действие основных фондов растет с 153,3 млн. руб. в 2005 г. до 247,1 млн. руб. в 2019 г. (в 2018г. 388,3 млн. руб.). На конец 2020 г. средний уровень использования производственных мощностей строительных организаций, по данным Смолстата - 61\%. За период с 2005 по 2019 года в отрасли происходило стабильное наращивание объема работ, выполненных по виду экономической деятельности «Строительство» [13] (рис.4). 


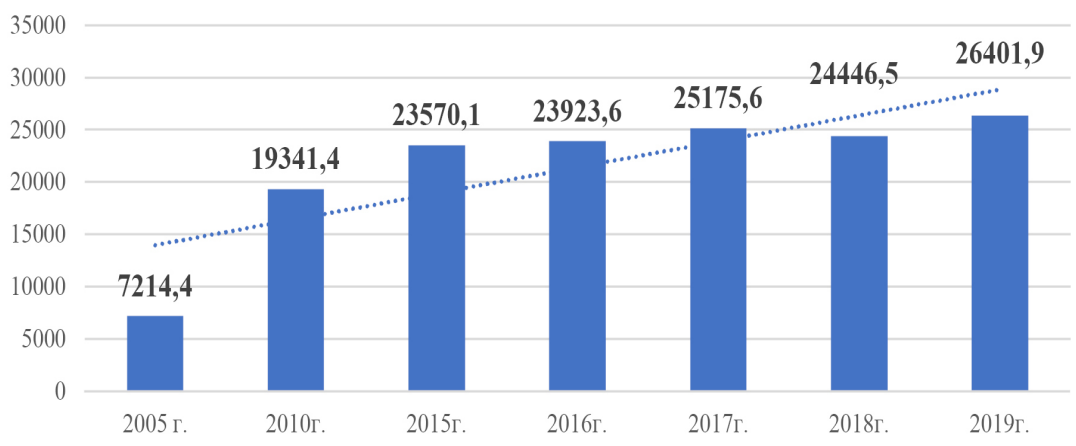

Рис. 4. Динамика объема работ, выполняемыми строительными компаниями в Смоленской области, млн. руб.

Можно отметить, что годовое введение в действие зданий выросло с 866 ед. (площадью и объемом соответственно, 302,7 тыс. м $^{2}$ и 1183,6 тыс.м $\left.{ }^{3}\right)$ в 2005 г. до 1872 ед. $\left(726,1\right.$ м $^{2} ; 3009,1$ м $\left.^{3}\right)$ в 2019 г., из них жилого назначения - с 861 (289,5 тыс. м²; 1158,9 тыс. м³) до 1768 (587,7 тыс. м²; 2084,3 тыс. м³), нежилого - с 5 (13,2 тыс. м²; $24,7$ тыс. м³ $)$ до 104 (138,4 тыс. м²; 924,8 тыс. м³). Из регионального проекта «Жильё» от 10.05.2019 г. прогнозируются обеспечение ввода годового объема жилья к 2024 г. не менее, чем 0,734 млн. м² [17]. За 2019 г. в условиях предкризисной ситуации происходит небольшое снижение объема строительства к уровню предыдущего года на 5,3\% (26401,9 млн. руб.), в том числе за 1 квартал - 13,6\%, за 2 квартал - 13,2\%, за 3 квартал - 3,7\%, но за 4 квартал - рост $8,8 \%$. В кризис 2020 г. (рост до 27229,6 млн. руб.) потери рынка (к аналогичному периоду 2019 г.) составили в 1 квартале - 6,8\%, во 2 квартале - 0\%, 3 квартал - 1,5\%, в 4 квартале - уже рост 1,4\%. На 01.10.2020 г. ипотечных жилищных кредитов выдано 12882 млн. руб., выше аналогичного периода 2019 г. на 28,5\%. Население обеспечено жильем на конец 2019 г. 29,4 м² на человека (в Страте-

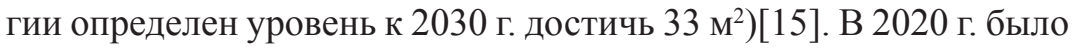
построено 5300 новых квартир, введено в эксплуатацию 56 МКД, населением построено 15841 жилых дома, площадь индивидуальной постройки составила 233,8 тыс. м². 
При этом в среднем по Смоленской области на начало 2020 г. доля комплексно благоустроенным жильем обеспечено 57,6\% жителей региона, на учете на получение жилья стоят 9,8 тыс. чел. Проект отраслевой Стратегии-2030 предполагает, что доля населения в РФ, удовлетворенного жилищными условиями и услугами, до 2024 года должна составить не менее $60 \%$, а к 2030 году — не менее $70 \%[13,15]$.

В 2020 г. в Смоленской области средняя стоимость строительства на $1 \mathrm{~m}^{2}$ общей площади по введенным в эксплуатацию МКД составляет 35532 руб. (в соседней Брянской области 31572 руб.), в том числе в сельской местности - 33949 руб., в городской - 34668 руб.

Исходя из данных Департамента экономического развития Смоленской области, в регионе строительство осуществляется для предприятий следующих отраслей (млн. руб.): производство атомной электроэнергии $(312,05)$, безалкогольной продукции (110), электротехнического оборудования (30), грунтов, субстратов, тукосмесей (1700), швейное производство (300), переработка древесины (270), сельскохозяйственное производство (14949,3), транспорт (1500), торговля (1630), аквапарк (1206), гостиница (500), складское хозяйство (300), культура (158), , прочие (685), всего: 23 650,35 млн. руб.; запланированы проекты в отраслевые объекты на предприятиях следующих отраслей: производство удобрений (22 386), ЖБИ (260), токопроводов (97), сельское хозяйство $(8870,6)$, перевооружение и реконструкция материально-технической базы $\mathrm{AO}$ «Смоленский авиационный завод» $(1112,9)$, производство ткани $(800)$ и обуви $(172,5)$, стекла $(500)$, добыча и переработка торфа (600), складское хозяйство (500), создание парк-отеля «Сады Голициных» (500), всего 35799 млн. руб.

Таким образом, в разные отрасли осуществляется и планируется возведение производственных и социальных объектов в объеме капитальных вложений на сумму 59, 5 млрд. руб., где приоритетом выступает сельское хозяйство и переработка сельскохозяйственного сырья (40\%), промышленность, транспорт и торговля, что соответствует специализации Смоленской области в советский период [18]. 
По опросам предпринимателей строительной отрасли в ходе исследования было выявлено, что индекс предпринимательской уверенности рос до конца 1 квартала 2020 г., затем было резкое его падение во 2 квартале до $30 \%$, но затем положение по индексу стабилизировалось на ежеквартальном снижении при базовом и консервативном вариантах от положения к началу года на $5-10 \%$, хотя они рассматривают уменьшение прогнозируемого портфеля заказов, который ими оценивается в среднем пессимистически: падение к концу 2021 г. на 20-35\%.

На основании оценки строительного рынка и сделанных прогнозов можно выделить следующие пути развития строительного рынка:

- совершенствование нормативно-законодательной базы в соответствии с требованиями экономического кризиса, санкций, сокращения внешнего финансирования;

- изменение налогообложения строительных компаний (особенно условий по налогообложению НДС и налога на имущество);

- повышение контроля за качеством сдаваемого жилья, объемами незавершенного строительства;

- изменение системы госзаказа и заключения договоров с государственными структурами, включая привлечение небольших компаний.

В условиях ужесточения конкуренции, кризиса, глобализации и мирового общественного разделения труда только переход на государственное регулирование и финансирование отечественной экономики может спасти отрасли, включая строительную, и рабочие места в регионах.

\section{Список литературы}

1. Анфимова А.И., Челак С.В. Особенности построения стратегии развития строительной компании // Неделя науки СПбПУ, материалы научного форума с международным участием. Инженерно-экономический институт. Санкт-Петербургский политехнический 
университет Петра Великого, Инженерно-экономический институт; Ответственные редактора: О.В. Калинина, С.В. Широкова. 2015. С. 388-390.

2. Арефьева А.А., Колдеева Е.В. Границы мирового рынка строительных услуг как основа изучения данного рынка // Экономист года 2016. Сборник статей II Международного научно-практического конкурса. Пенза, 2016. С. 87-91.

3. Кузьмич Н.П. Воздействие строительного рынка на рынок жилищной недвижимости в контексте эффективного использования земельных ресурсов // Общество: политика, экономика, право. 2016. № 9. С. 38-40.

4. Кутлыева Г.М., Смирнова А.С. Формирование стратегии развития компаний строительной отрасли // Труды VIII Международной научно-практической конференции «Инженерные системы - 2015». Российский университет дружбы народов; Под редакцией Н.К. Пономарева. 2015. С. 410-414.

5. Семененко В.Ю. Страны с развивающимися рынками на мировом рынке строительных услуг // Russian Economic Bulletin. 2020. T. 3, №3. C. 121-127.

6. Фоменко А.А. Оценка базовых стратегий факторов конкурентоспособности строительной компании // Уральский научный вестник. 2016. Т.4, №2. С. 57-70.

7. Черепухин Т.Ю., Забабурина Н.В., Бибиков К.А. Строительный рынок - особенности и перспективы развития отрасли и рынка в России // 21 век: фундаментальная наука и технологии. Материалы XV международной научно-практичсекой конференции. 2018. С. 86-91.

8. Häkkinen T. Assessment of indicators for sustainable urban construction. 2007. P. 247-259.

9. Lowe I. Shaping a sustainable future - an outline of the transition. 2009. P. 247-254.

10. Sev Aysin A comparative analysis of building environmental assessment tools and suggestions for regional adaptations. 2011. P. 231-245.

11. Huang R.- Y., Hsu W. Framework development for state-level appraisal indicators of sustainable construction. 2010. P.143-164. 
12. Olagnero M. La questione abitativa e i suoi dilemmi // Meridiana. 2008. No. 62. P. 21-35.

13. Статистический ежегодник Смоленской области. 2020: Стат. сб./ Смоленскстат. С., 2020. 551 c. https://sml.gks.ru/storage/mediabank/4R9S0N1K/esmc2020.pdf

14. Постановление Администрации Смоленской области от 29 декабря 2018 г. № 981 «Об утверждении стратегии социально-экономического развития Смоленской области до 2030 года». https://econ. admin-smolensk.ru/files/410/strategiya-socialno-ekonomicheskogorazvitiya-smolenskoj-oblasti-do-2030-goda-v-red-postanovleniyaot-19-05-2020-2.pdf

15. Проект Стратегия развития строительной отрасли Российской Федерации до 2030 года. https://www.srogen.ru/upload/files/documents/ strategy_text_13112019.pdf

16. Приказ Министерства регионального развития Российской Федерации от 30 декабря 2009 года N 624 (с изменениями на 14 ноября 2011 года) «Об утверждении Перечня видов работ по инженерным изысканиям, по подготовке проектной документации, по строительству, реконструкции, капитальному ремонту объектов капитального строительства, которые оказывают влияние на безопасность объектов капитального строительства». http://www. consultant.ru/document/cons_doc_LAW_97156/

17. Региональный проект «Жильё». https://stjkh.admin-smolensk.ru/

18. Мониторинг социально-экономического развития Смоленской области. https://econ.admin-smolensk.ru/files/378/socialno-ekonomichsmolensk-za-3-kv-2020g-1.pdf

\section{References}

1. Anfimova A.I., Chelak S.V. Osobennosti postroeniya strategii razvi-tiya stroitel'noy kompanii [Features of building a development strategy for a construction company]. Nedelya nauki $S P b P U$, materialy nauchnogo foruma s mezhdunarodnym uchastiem [SPbPU Science Week, materials of a scientific forum with international participation]. Engineering and Economics Institute. Peter the Great St. Petersburg Poly- 
technic University, Engineering and Economics Institute; editors: O.V. Kalinina, S.V. Shirokova, 2015, pp. 388-390.

2. Aref'eva A.A., Koldeeva E.V. Granitsy mirovogo rynka stroitel'nykh uslug kak osnova izucheniya dannogo rynka [The boundaries of the world market of construction services as the basis for studying this market]. Ekonomist goda 2016. Sbornik statey II Mezhdunarodnogo nauchno-prakticheskogo konkursa [Economist of the Year 2016. Collection of articles of the II International Scientific and Practical Competition]. Penza, 2016, pp. 87-91.

3. Kuz'mich N.P. Vozdeystvie stroitel'nogo rynka na rynok zhilishchnoy nedvizhimosti $\mathrm{v}$ kontekste effektivnogo ispol'zovaniya zemel'nykh resursov [The impact of the construction market on the residential real estate market in the context of the effective use of land resources]. $\mathrm{Ob}$ shchestvo: politika, ekonomika, pravo, 2016, no. 9, pp. 38-40.

4. Kutlyeva G.M., Smirnova A.S. Formirovanie strategii razvitiya kompaniy stroitel'noy otrasli [Formation of a development strategy for companies in the construction industry]. Trudy VIII Mezhdunarodnoy nauchno-prakticheskoy konferentsii «Inzhenernye sistemy - 2015» [Proceedings of the VIII International Scientific and Practical Conference “Engineering Systems - 2015]. Peoples' Friendship University of Russia; Ed. N.K. Ponomarev, 2015, pp. 410-414.

5. Semenenko V.Yu. Strany s razvivayushchimisya rynkami na mirovom rynke stroitel'nykh uslug [Countries with emerging markets in the global construction services market]. Russian Economic Bulletin, 2020, vol. 3, no. 3, pp. 121-127.

6. Fomenko A.A. Otsenka bazovykh strategiy faktorov konkurentosposobnosti stroitel'noy kompanii [Assessment of basic strategies of factors of competitiveness of a construction company]. Ural'skiy nauchnyy vestnik, 2016, vol. 4, no. 2, pp. 57-70.

7. Cherepukhin T.Yu., Zababurina N.V., Bibikov K.A. Stroitel'nyy rynok - osobennosti i perspektivy razvitiya otrasli i rynka v Rossii [Construction market - features and prospects for the development of the industry and the market in Russia]. 21 vek: fundamental'naya nauka i tekhnologii. Materialy XV mezhdunarodnoy nauchno-praktichsekoy konferentsii [21st century: fundamental science and technology. Mate- 
rials of the XV international scientific and practical conference]. 2018, pp. 86-91.

8. Häkkinen T. Assessment of indicators for sustainable urban construction. 2007, pp. 247-259.

9. Lowe I. Shaping a sustainable future - an outline of the transition. 2009, pp. 247-254.

10. Sev Aysin A comparative analysis of building environmental assessment tools and suggestions for regional adaptations. 2011, pp. 231-245.

11. Huang R.- Y., Hsu W. Framework development for state-level appraisal indicators of sustainable construction. 2010, pp.143-164.

12. Olagnero M. La questione abitativa e i suoi dilemma. Meridiana, 2008, no. 62 , pp. 21-35.

13. Statistical Yearbook of the Smolensk Region. 2020: Stat. sb./ Smolenskstat. S., 2020, 551 p. https://sml.gks.ru/storage/mediabank/4R9S0NlK/ esmc2020.pdf

14. Resolution of the Administration of the Smolensk region dated December 29, 2018 No. 981 "On approval of the strategy of socio-economic development of the Smolensk region until 2030". https://econ. admin-smolensk.ru/files/410/strategiya-socialno-ekonomicheskogo-razvitiya-smolenskoj-oblasti-do-2030-goda-v-red-postanovleniya-ot-19-05-2020-2.pdf

15. Draft Strategy for the development of the construction industry of the Russian Federation until 2030. https://www.srogen.ru/upload/files/documents/strategy_text_13112019.pdf

16. Order of the Ministry of Regional Development of the Russian Federation of December 30, 2009 N 624 (as amended on November 14, 2011) "On approval of the List of types of work on engineering surveys, on the preparation of project documentation, on construction, reconstruction, overhaul of capital construction, which have an impact on the safety of capital construction projects". http://www.consultant. ru/document/cons_doc_LAW_97156/

17. 'Zhile' Regional project. https://stjkh.admin-smolensk.ru/

18. Monitoring the socio-economic development of the Smolensk region. https://econ.admin-smolensk.ru/files/378/socialno-ekonomich-smolensk-za-3-kv-2020g-1.pdf 


\section{ДАННЫЕ ОБ АВТОРЕ}

Сапожникова Светлана Михайловна, доцент кафедры «Экономика», кандидат экономических наук

Смоленский государственньй университет

ул. Пржевальского, 4, г. Смоленск, 214010, Российская Федерачия

ssm0668@mail.ru

\section{DATA ABOUT THE AUTHOR}

Svetlana M. Sapozhnikova, Associate Professor of the Department of Economics, Candidate of Economic Sciences

Smolensk State University

4, Przhevalsky Str., Smolensk, 214010, Russian Federation ssm0668@mail.ru

ORCID: 0000-0002-1167-1999 